\title{
Como o Brasil tem enfrentado o tema provimento de médicos?
}

\author{
How has Brazil dealt with the topic of provision of physicians?
}

¿Cómo ha enfrentado Brasil la cuestión de la provisión de médicos?

Mônica Sampaio de Carvalho ${ }^{1}$

Maria Fátima de Sousa ${ }^{2}$

The aim was to analyze how Brazil has dealt with the shortage of physicians and the attempts to overcome the situation in coordination with healthcare policies and strategies for training and establishment of these professionals in accordance with the needs of the Brazilian National Health System (SUS). PROVAB (Program for Primary Care Enhancement), created by the federal government in 2011, was used as a case study. This seeks to provide healthcare professionals to localities in need. The program offers a score of $10 \%$ in residency examinations after evaluation of the professional and structured distance education activities and supervision. PROVAB was analyzed within the current context of the work management and healthcare education policies, in order to comprehend its implementation through discussions, movements, events and qualitativequantitative data available from the Ministry of Health. Ways to develop work management and healthcare education in Brazil are indicated.

Keywords: PROVAB. Primary health care. Medical education. Professional practice. Continuing education.

\begin{abstract}
Analisa-se como o Brasil tem enfrentado a carência de médicos nas tentativa de superar a situação de forma articulada com as políticas de saúde e estratégias de formação e fixação desses profissionais, de acordo com as necessidades do Sistema Único de Saúde (SUS). Tomou-se como estudo de caso o Programa de Valorização da Atenção Básica (PROVAB) criado pelo governo federal em 2011, que busca prover profissionais de saúde para as localidades necessitadas, destacando-se as seguintes ofertas do programa: pontuação de $10 \%$ nas provas de residência após avaliação do profissional e atividades estruturadas de educação a distância e supervisão. $O$ PROVAB foi analisado dentro do contexto atual da política de Gestão do Trabalho e da Educação na Saúde, na tentativa de compreender sua implementação mediante discursos, movimentos, acontecimentos e dados qualitativos e quantitativos, disponibilizados pelo Ministério da Saúde.Dessa forma, apontam-se caminhos para o desenvolvimento da Gestão do Trabalho e da Educação na Saúde no Brasil.
\end{abstract}

Palavras-chave: PROVAB. Atenção Básica à Saúde. Educação médica. Prática profissional. Educação permanente.
${ }^{1}$ Doutoranda, Universidade de Brasília (UnB). Faculdade de Ciências da Saúde, Campus Universitário Darcy Ribeiro. Brasília, DF, Brasil. 70910-900. monicarvalho19@ gmail.com ${ }^{2}$ Departamento de Saúde Coletiva, UnB. 


\section{Introdução}

Entre as perspectivas de estudo do tema da saúde com destaque crescente nos últimos anos, está o campo temático da gestão do trabalho e da educação. Os estudos, inicialmente articulados em torno da administração, enfocam a força de trabalho como "recurso" sob o ponto de vista taylorista de produção no trabalho.

Os estudos clássicos de Maria Cecília Donnangelo (1975; Donnangelo, Pereira, 1979) analisam, a partir das ciências sociais, o trabalho médico e a diversificação das especializações no interior dos hospitais. No mesmo sentido, estão os estudos de Ricardo Bruno Mendes Gonçalves (1992, 1978), que introduz o conceito de processo de trabalho e aborda, por meio da óptica marxista, o processo de produção, as tecnologias e os saberes que servem de base para os estudos de Emerson Merhy (2002, 1997), com a micropolítica do trabalho vivo em ato na saúde, este ampliando para os esquizonalistas como Deleuze e Guatarri, assim como Gastão Wagner de Souza Campos (2000), que critica a abordagem gerencial hegemônica e o taylorismo.

Esses autores criticam, no contexto da formação e do trabalho, a fragmentação e a especialização crescentes, do mesmo modo, a abordagem gerencialista, que toma o trabalho e o trabalhador como "recurso" a ser talhado e administrado, segundo os interesses da direção de serviços e sistemas (Ceccim, 2005).

O grande aumento do número de postos de trabalho, com a aguda expansão de cobertura assistencial da Atenção Básica, produzida pela progressiva implantação do Sistema Único de Saúde (SUS), torna a temática estratégica não apenas na perspectiva de propor estratégias de provimento e de fixação profissionais de saúde, mas também aponta a necessidade de investir no processo de formação médica e de educação permanente dos trabalhadores do SUS de acordo com o modelo assistencial centrado no cuidado em saúde.

Embora a regulação da formação profissional já é uma premissa presente desde a Constituição brasileira em seu artigo 200 que estabelece a competência do Sistema Único de Saúde em "ordenar a formação de recursos humanos na área da saúde", sendo reforçada pela Lei Orgânica da Saúde, na qual explicita no artigo 15, item IX, a responsabilidade do sistema de saúde "[...] na formulação e na execução da política de formação e desenvolvimento de recursos humanos para a saúde" (Brasil, 1990, p.18055), sendo tema de diversas conferências de saúde com propostas que vão desde a regulamentação do artigo 200 da Constituição brasileira, fomento a capacitações, educação continuada, educação permanente, política de provimento, mudanças na graduação, reforma nos currículos, formação de especialistas de acordo com as necessidades do SUS, carreira, melhores condições salariais e de trabalho (Ceccim, Armani, Rocha, 2002), pautas estas reforçadas com a criação da SGTES (Secretaria de Gestão do Trabalho e da Educação na Saúde) em 2003, na prática, ainda tem desafios importantes a serem enfrentados no que diz respeito aos processos regulatórios e a política de gestão do trabalho e de educação na saúde.

Este artigo é parte do estudo que teve por objetivo analisar como o Brasil tem buscado enfrentar um problema crônico no SUS, que é a falta de médicos para atuarem nos serviços públicos de saúde, sobretudo, na Atenção Básica à Saúde. Esse problema vem comprometendo significativamente as gestões municipais e estaduais do sistema de saúde há pelo menos uma década, com algumas tentativas governamentais de buscar soluções para essa questão, com visões diversas a respeito do tema e que disputam uma hegemonia no discurso e na prática. Para isso, foi realizada a análise do processo de implementação do Programa de Valorização da Atenção Básica (PROVAB), política de provimento do Ministério da Saúde do Brasil desde dezembro de 2011 e suas repercussões entre os diversos atores governamentais, corporações e profissionais para extrair elementos essenciais dos movimentos, visões e relações de poder existentes (Foucault, 1996). 


\section{Método}

Trata-se de pesquisa histórica de caráter exploratório associado a um estudo de caso, o PROVAB, e está no campo da investigação social. Segundo Minayo (2004, p.13), o "objeto das Ciências Sociais é histórico" e carregado de significados, intencionalidades de grupos, da sociedade em geral e de visão ideológica de mundo, trazendo a implicação do sujeito no estudo.

Goode e Hatt (1969), Yin (1989), e Bonoma (1985) apud Minayo (2006, p.164) abordam o estudo de caso como um método que utiliza "estratégias de investigação qualitativa para mapear, descrever e analisar o contexto, as relações e as percepções a respeito da situação, fenômeno ou episódio em questão".

Foram utilizadas como categorias analíticas o poder, o saber, o trabalho e a meritocracia.

Os aspectos analisados dessas categorias estão no campo político e das ciências sociais a partir das posições dos atores estratégicos em relação ao PROVAB, do processo de trabalho, da proposta pedagógica do PROVAB e da visão de meritocracia.

Alguns recortes ao objeto foram utilizados como referenciais de análise: a formação médica, a educação permanente, os saberes tecnológicos, o poder médico, a relação médico-paciente, a autonomia, a disputa entre corporações e governo e o poder, entre outros.

O processo de observação e pesquisa foi por meio de análise documental e análise dos dados secundários da Atenção Básica qualitativos e quantitativos oriundos do Sistema de Informação e de Gestão do PROVAB (SIGPROVAB/SGTES/MS), do Formulário Eletrônico do SUS (FormSUS/SGTES/MS) e da Plataforma Arouca / Universidade Aberta do SUS (UnA-SUS/SGTES/MS) e observação de seminários, reuniões e oficinas com os atores envolvidos no processo.

\section{As políticas de provimento e a Atenção Básica no Brasil - um caminho a ser percorrido}

O Decreto $n^{\circ} 7.508$, promulgado em junho de 2011 que regulamenta a Lei 8.080/1990, reforça o papel da Atenção Básica, uma vez que define "[...] Atenção Básica como porta de entrada preferencial do sistema" e "ordenadora da rede e do cuidado em saúde" (Brasil, 2011a, p.7).

Por ser a porta de entrada prioritária do sistema de saúde, compete à Atenção Básica, segundo o decreto supracitado, assegurar aos usuários "[...] acesso universal, contínuo e de qualidade" e "a integralidade da atenção e do cuidado", tanto individual como coletiva para dentro da Unidade Básica de Saúde e para fora na Rede de Atenção à Saúde (Brasil, 2012a, p.21).

A alta rotatividade dos médicos na atenção básica, entretanto, associado à total escassez em algumas localidades, compromete a continuidade do cuidado e consequentemente a qualidade dos serviços ofertados. Estudo feito por Campos e Malik (2008) realizado no Estado de São Paulo sobre satisfação de médicos no Programa de Saúde da Família mostra os fatores que contribuem para a rotatividade de médicos nas unidades básicas de saúde que são principalmente a distância, a falta de condições materiais e de capacitação.

Capozzolo (2003), em sua tese de doutorado, analisando as condições de trabalho das equipes de saúde da família, considera que a sobrecarga de trabalho, a falta de medicamentos, materiais e retaguarda de outros níveis de atenção, além da insegurança gerada pela falta de capacitação dos profissionais para exercer a prática de generalista, levariam à alta rotatividade dos médicos.

Outro dado relevante do estudo de Campos e Malik (2008) é que, embora o salário seja um dos atrativos para os médicos se apresentarem para contratação no programa, este não tem garantido a sua fixação. Atribui-se ao fato de que, em geral, as melhores propostas remuneratórias são em áreas longínquas e pouco atrativas em termos de desenvolvimento econômico e sociocultural, forte fator de retenção de médicos já demonstrado em pesquisas realizadas. 
Essa análise coincide com o estudo de Girardi, Pierantoni e Dal Poz (2012), sobre o índice de escassez de profissionais da Atenção Básica, utilizando o método Full Time Equivalent (FTE) e os parâmetros de um médico na Atenção Básica para cada três mil pessoas, por meio dos quais observou-se que as regiões de maior escassez são aquelas em que há uma elevada mortalidade infantil e utilização do Programa Bolsa Família, ou seja, áreas desprovidas de serviços e que, portanto, mais sofrem com o acesso à saúde.

Essas dificuldades de provimento e fixação de médicos na Atenção Básica têm repercutido no acesso e na qualidade dos serviços prestados, o que revela o Índice de Desempenho do SUS (IDSUS), "um indicador-síntese" do Ministério da Saúde, que mede o acesso e a efetividade do sistema. O reflexo destas dificuldades tem gerado insatisfação por parte dos usuários com o SUS.

Associado aos fatores acima sinalizados, a baixa responsabilização do sistema de saúde no atendimento às necessidades do usuário nos serviços e a baixa qualidade e resolutividade da Atenção Básica no Brasil contribuem também para o agravamento da situação.

Há necessidade, portanto, de, além de prover profissionais para a atenção básica, articular mecanismos para fixação desses profissionais nos serviços e propor mudanças no modelo de atenção e cuidado à saúde e na formação médica.

\section{As políticas de indução para provimento e fixação de profissionais estabelecidas no Brasil e no Mundo}

Há vários mecanismos utilizados pelos países para prover profissionais de saúde, que vão desde as propostas mais voluntaristas até ações articuladas com incentivos, por exemplo, bolsa com auxílios alimentação e moradia, alguns propõem processos de educação continuada com envolvimento de instituições universitárias e em outros casos a atuação nessas áreas tornou-se pré-requisito para a obtenção de registro profissional, créditos educativos e ingresso em especialidades médicas ou bolsas de pós-graduação. Ainda há outros que articulam carreira com provimento.

Maciel Filho (2007) descreve, em sua tese de doutorado, as estratégias de alguns países para enfrentamento desse problema e o histórico dos programas de provimento no Brasil. Relata a experiência de serviço civil obrigatório no Peru, Equador, na Costa Rica, Colômbia e no México, sendo este, a experiência mais consolidada, adotada desde 1945 por meio dos centros rurais cooperativos, em que o estudante permanece por 12 meses no local como requisito obrigatório para obter o registro de médico.

Outras experiências observadas articulam provimento e carreira sanitária, como no Chile, considerando distâncias geográficas, o risco, e prevendo estrutura e condições de trabalho, ascensão profissional e oportunidades de desenvolvimento técnico (Maciel Filho, 2007).

$\mathrm{Na}$ Austrália, busca-se prover profissionais por meio de bolsas de estudo para os estudantes ingressarem em cursos de medicina, sendo obrigatória, nos currículos, a atuação da escola médica em áreas rurais e remotas, além de tornar obrigatória a atuação por seis meses dos profissionais que se formam em Clínica Geral (Maciel Filho, 2007).

No início dos anos 1990, o tema do provimento de médicos foi considerado um dos pontos críticos do sistema de saúde no Canadá (Campos, Girardi, Machado, 2009).

No Brasil, os programas de provimento e fixação remontam à época da ditadura militar, que implementou o Projeto Rondon: iniciativa com o objetivo de levar estudantes a atuarem em locais de difícil acesso, expandindo ações e serviços de saúde (Maciel Filho, 2007).

Ainda, nesse período, surge o Programa de Interiorização das Ações de Saúde e Saneamento (PIASS), o Programa de Interiorização do Sistema Único de Saúde (PISUS) e o Programa de Interiorização do Trabalho em Saúde (PITS), sendo este uma das estratégias de fortalecimento do Programa Saúde da Família (PSF), que estava surgindo à época e foi responsável pela ampliação do acesso e da cobertura assistencial de várias localidades carentes de atendimento à saúde. Maciel Filho (2007) relata minuciosamente, em sua tese de doutorado, as iniciativas de enfrentamento dessa questão pelo Brasil.

O PITS, programa anterior ao PROVAB teve por objetivo ampliar a cobertura do PSF por meio do provimento de médicos e enfermeiros em áreas cujo PSF ainda não tenham sido implementado. As 
ofertas apresentadas para os profissionais eram bolsa federal e formação profissional, como tutoria e supervisão continuada semipresencial contratada pelo CNPQ, cursos autoinstrucionais, curso introdutório do PSF, curso de especialização em saúde da família, seguro de vida e acidentes pessoais, moradia, alimentação, transporte e certificação. Apesar do grande número de inscritos, apenas trezentos municípios, 421 profissionais, sendo 181 médicos e duzentos e quarenta enfermeiros, concluíram o programa.

Embora o Estado tenha se esforçado para instituir políticas de provimento ao longo de todos estes períodos, sendo estas responsáveis pela inserção de vários profissionais nesta experiência, segundo Médici (1993 apud Maciel Filho, 2007), essas medidas não foram suficientes por si só para enfrentar o problema da má distribuição de médicos no País e, consequentemente, da fixação. Alguns fatores influenciam nesse processo, entre eles, o fator econômico e social, como importantes fatores impeditivos de fixação, as condições de trabalho e a possibilidade de formação e capacitação.

Desde 2011, o Ministério da Saúde, em parceria com o Ministério da Educação, baseado no Plano Nacional de Saúde, resolveu lançar um conjunto de medidas que buscam atrair profissionais de saúde, mais especificamente médicos, nas localidades necessárias. Entre essas medidas, destacam-se:

1 O Fundo de Financiamento ao Estudante do Ensino Superior (FIES), criado pela Medida Provisória $n^{\circ} 1.827$, de 27/05/99, regulamentado pelas Portarias MEC no 860, de 27/05/99 e 1.386/99, de 15/ 19/99 e Resolução do Conselho Monetário Nacional 2647, de 22/09/99. Em 2010, através da Lei no12.202/2010, o governo ampliou os benefícios para os médicos que atuam na Atenção Básica em regiões prioritárias para o SUS.

2 Vinda de médicos estrangeiros no país por meio de termo de cooperação internacional com o Governo Brasileiro e revisão do processo de revalidação de diplomas no Brasil, o Revalida;

3 Ampliação da oferta de vagas de cursos de medicina em localidades com rede de atenção estruturada e com condições de funcionamento de acordo com os elementos das novas portarias $\mathrm{GM}$ / MEC $n^{\circ} 1 / 2013$ e portaria GM/MEC $n^{\circ} 2 / 2013$. Nesses cursos, busca-se desenvolver um projeto pedagógico voltado para atender à integralidade do cuidado e as redes de atenção à saúde;

4 O PROVAB que objetiva prover e incentivar profissionais a atuarem na atenção básica, por meio de estratégias de educação à distância e supervisão pedagógica articulada ao "bônus" de 10\% nas provas de residência médica para aqueles que tiverem interesse em ingressar nos programas de residência;

5 Expansão de residências médicas como importante estratégia de fixação e de formação de médicos para o sistema de saúde.

Essas várias estratégias estão sendo implementadas em tempos diferentes e compõem o escopo da política de fortalecimento da Atenção Básica do Governo Federal.

O PROVAB, programa criado pelo Ministério da Saúde para prover médicos, enfermeiros e cirurgiões-dentistas prioritariamente em áreas de difícil acesso ou em populações vulneráveis, também prevê estratégias de educação à distância, como a especialização em Saúde da Família e telessaúde, atividades de supervisão presencial e à distância, além do bônus de 10\% para os médicos que pretenderem ingressar em Programas de Residência Médica a partir de uma avaliação de desempenho (Brasil, 2011b).

A gestão do Programa, em sua primeira versão, é centralizada na União, destacando por meio de Portaria Interministerial 2.087/2011, o papel do município na contratação dos profissionais de saúde e evidenciando uma ausência do papel do Estado, papel que foi sendo construído gradativamente através das oficinas realizadas para repactuação com os entes federativos e universidades neste processo.

Em termos de abrangência, diferentemente do Projeto Rondon e do PITS, o PROVAB 2012 permitiu com que os 5.565 municípios brasileiros pudessem concorrer a uma vaga, manifestando a sua adesão de acordo com cinco perfis articulam critérios como capital e região metropolitana, municípios beneficiados pelo FIES, população rural com extrema pobreza.

Na primeira versão do programa, segundo dados do SIGPROVAB, foram inscritos 2.176 municípios. Deste total, foram selecionados novecentos e cinquenta municípios para receberem 4.671 profissionais de saúde. A Tabela 1 mostra o percentual de profissionais selecionados e contratados pelo programa, assim como 0 percentual de retenção. 
Tabela 2. Quantitativo de profissionais selecionados e contratados no PROVAB e percentual de retenção

\begin{tabular}{lccc}
\hline Profissionais & Selecionados & Contratados & Percentual de retenção \\
\hline Médicos & 1.460 & 381 & $26 \%$ \\
Enfermeiros & 1.889 & 126 & $6,67 \%$ \\
Dentistas & 1.322 & 110 & $8,32 \%$ \\
Total & 4.671 & 617 & $13,2 \%$ \\
\hline
\end{tabular}

Fonte: SIGPROVAB, Departamento de Gestão da Educação na Saúde(DEGES)/

Secretaria de Gestão do Trabalho e da Educação na Saúde (SGTES)

Ainda segundo dados do SIGPROVAB/SGTES/MS, os médicos estão distribuídos por região do País, na seguinte proporção: região Nordeste (67\%), seguida das regiões Sudeste (20\%), Centro-Oeste $(6 \%)$, Sul $(5 \%)$ e Norte $(2 \%)$.

Este baixo percentual de retenção de médicos pode ter várias explicações, uma delas estão relacionados a problemas de comunicação, instabilidade contratual por meio dos municípios e mobilizações de segmentos da medicina e algumas instituições de ensino na tentativa de desestabilizar o programa. Muitos dos relatos atribuem este fenômeno a informações pouco precisas que chegavam à "ponta do sistema", gerando confusão e insegurança por parte dos profissionais de saúde. Muitos municípios, por sua vez, desconheciam as regras estabelecidas em edital e quais as responsabilidades dos gestores frente ao programa, mais especificamente no tocante à contratação de profissionais. Alguns profissionais tinham a expectativa de vantagens acima dos valores de mercado local e acordos contratuais de jornada parcial de trabalho. Além disso, alguns profissionais, segundo relatos, depararam-se com situações insalubres para o exercício da profissão. Outros decidiram por ingressar nos programas de residência, após a publicação dos resultados das provas. Somado a tudo isso, os atrasos nas contratações geraram instabilidade por parte dos profissionais, mais especificamente médicos, que tinham como expectativa o cumprimento de um ano para realização das provas de residência no final do ano.

No caso dos enfermeiros e dos dentistas, o problema estava mais relacionado à oferta de mercado, já abordada, resultando no desinteresse por esses profissionais pelos municípios. A alternativa aí apresentada pelo Ministério da Saúde foi então o Curso de Especialização em Atenção Básica pelo Sistema UnA-SUS com bolsa de estudos na modalidade trabalhador - estudante. Essa estratégia resultou em 1.147 bolsistas contratados entre enfermeiros e dentistas.

O Curso de Especialização com foco em Atenção Básica, constitui-se como uma oferta do PROVAB, ainda não obrigatória na primeira fase, executado por instituições de ensino vinculadas ao UnA-SUS (Universidade Aberta do SUS - rede criada por Decreto $n^{\circ} 7.385 / 2012$, de 8 de dezembro de 2010 com o objetivo de oferecer ações de educação a distância.

A supervisão, obrigatória para médicos no PROVAB, acabou se restringindo a esta categoria e o curso de especialização para os enfermeiros e dentistas prioritariamente uma vez que esta oferta não obrigatória na primeira versão teve uma baixa adesão dos médicos.

A supervisão definida por categoria profissional e com forte vinculação às Instituições de Ensino Superior teria o objetivo de coordenar e sistematizar o processo de avaliação para fins de pontuação das provas de residência.

O processo de discussão com a equipe do DEGES levou à necessidade de ampliar o escopo de atuação deste supervisor, introduzindo conceitos de educação permanente, apoio matricial, campo e núcleo de atuação profissional. A grande questão era, portanto, definir se a supervisão atuaria apenas no campo e no núcleo profissional ou apenas no núcleo como pensado inicialmente.

Ao longo do processo, foram introduzidas como atividades de supervisão a realização de um diagnóstico inicial do território e do processo de trabalho da equipe vinculada ao profissional supervisionado, elaboração de plano de educação permanente e projetos de intervenção por parte dos profissionais no território. 
Entretanto, as disputas no âmbito do papel da supervisão e as pactuações já estabelecidas com as instituições de ensino, com a corporação e a Comissão Nacional de Residência Médica fizeram prevalecer o modelo inicial de supervisão médica com foco no processo avaliativo para fins de pontuação nos programas de residência.

\section{Poder, saber, trabalho e meritocracia: afinal como se revelam os atores neste processo?}

Ao analisar as características dos programas de provimento no Brasil observam-se, no aspecto político, dificuldades no âmbito governamental nas primeiras experiências por conta dos regimes totalitários e da transição democrática em que vivia o país; enquanto, no momento atual, os entraves políticos são de natureza coorporativa.

Em relação ao provimento de médicos no Brasil, há uma posição clara dos gestores do SUS, no sentido de que faltam médicos no País e temos importantes vazios assistenciais decorrentes dessa escassez. Recentemente, no Encontro dos Prefeitos, em Brasília, ocorrido em janeiro de 2013, a Frente Nacional de Prefeitos criou uma campanha intitulada "cadê o médico?" reivindicando medidas ao governo federal para prover médicos nas diversas regiões do País. Entre as propostas deste segmento, destaca-se a flexibilização de regras para a entrada de médicos estrangeiros para atuarem na atenção básica.

Esse pensamento é reforçado pelo gestor federal em seu discurso onde defende, baseado na análise comparativa da proporção de médicos por habitantes no Brasil e em outros países que implantaram sistemas de saúde universais, que há escassez e má distribuição de médicos nas regiões brasileiras. Um dos argumentos se dá através da relação de médicos por habitante no país, que hoje tem a média de 1,8 médico por habitante.

De fato, quando se faz uma análise comparativa em países com sistemas de saúde organizados tomando a Atenção Básica como prioritária, observa-se uma proporção maior de médicos por habitante, a exemplo, na Inglaterra cuja relação é de 2,7 médicos/habitante, em Portugal 3,87 médicos/habitante, na Espanha, 3,96 médicos/habitante e na Argentina, 3,2 médicos/habitante.

Esses argumentos também se baseiam em estudos de Girardi, Pierantoni e Dal Poz (2012) em que se comprova por meio de pesquisa feita pelo Observatório de Recursos Humanos do NESCOM/UFMG (Núcleo de Saúde da Comunidade/ Universidade de Minas Gerais), pela qual o autor analisa a proporção de egressos e o primeiro emprego. Observa-se, no caso da medicina, um mercado de trabalho extremamente favorável para os egressos de medicina no Brasil com oferta satisfatória de emprego, diferentemente do que se observa em outras profissões da saúde como é o caso da enfermagem cuja proporção de egressos versus empregabilidade é inversa, com provável desemprego.

Setores da medicina, como as corporações médicas, acreditam, entretanto, que o problema não é escassez de médicos, e sim má distribuição e pouca atratividade do setor público, principalmente, no que se refere às condições de trabalho e remuneração. Defendem, portanto, que há médicos suficientes no país por meio de estudo recentemente publicado intitulado Demografia Médica no Brasil. Nele reforçam a necessidade de uma carreira nacional para a saúde semelhante à carreira do Poder Judiciário e afirmam que o país possui, atualmente, 371.788 médicos em atividade e que, na década de 1970, havia apenas 58.994 médicos. Houve, então, um crescimento de $530 \%$. Nesse sentido, acreditam que com um grande percentual de médicos jovens e com o aumento de vagas de cursos de medicina, o estoque de médicos é suficiente para atender à demanda (CFM/IBGE, 2011).

Em recentes pesquisas realizadas por Girardi, Pierantoni e Dal Poz (2012) com médicos da região Norte e pela Fundação Saúde da Família da Bahia (FESF/BA) com médicos dessa Fundação ambas revelaram que os principais fatores de atração do médico, além das condições sócio - econômicas da localidade e da oferta de bens e serviços, são a remuneração, as condições de trabalho (entendido aqui como volume de trabalho, equipamentos, materiais, entre outros) e a possibilidade de formação continuada. A possibilidade de carreira não foi o principal fator atrativo no estudo de Girardi, Pierantoni e Dal Poz (2012), embora ela apareça na proporção de 23,08\%. 
Ao analisar os discursos, observamos relações de poder e poder - saber instituídas e instituintes nesse processo. O instituído é evidenciado pela necessidade de preservação da lógica atual de inserção de médicos especialistas no mercado de trabalho através da Residência Médica e da lógica de titulação pela Associação Médica Brasileira (AMB). Entretanto, o instituinte estabelecido pelo governo federal e pelos prefeitos provoca uma certa desestabilização e desorganiza a ordem do instituído no campo molar da conformação da política através da modificação dos critérios de ingressos nos programas de residência a partir do trabalho na Atenção Básica e no campo molecular à medida em que este médico, seja do PROVAB ou seja de outro país, ambos passam a atuar nos territórios de prática, interagindo com as equipes, com as universidades através da supervisão e com a gestão local da unidade de saúde.

Foucault (1999) discute o poder como uma prática social, fruto das interações e relações estabelecidas. Para esse autor, além do poder do Estado, o poder encontra-se em todos os lugares, exercendo certa molecularidade e molaridade. Ainda na obra de Foucault intitulada Microfísica do Poder, Roberto Machado escreve no prefácio o ponto de vista do autor sobre poder e relata que o: "[...] poder é algo que se exerce, que se efetua e que funciona, não é um lugar que se ocupa, nem um objeto que se possui. Ele se exerce, se disputa e, nesta relação unívoca, unilateral; nessa disputa ou se ganha ou se perde". (Foucault apud Machado, 1996, p.XV)

Ainda segundo Foucault (1975 apud Santos, 2000), o pensamento liberal procura identificar o poder social como o poder do Estado, mas, nas sociedades modernas, surgiu outra forma de poder, bem mais sofisticado e eficaz: o poder-saber disciplinar, caracterizado pelo poder de normalizar as subjetividades e controlar as sociedades.

O poder disciplinar necessariamente não é uma instituição, mas um dispositivo, um método de sujeição constante de forças e imposição de uma "relação de docilidade - utilidade" para o bom funcionamento e manutenção de uma sociedade industrial e capitalista, conforme Foucault (apud Machado, 1996, p.XV).

Também chamado de biopoder, este se aplica à população, à vida e aos vivos por meio das sujeições decorrentes da normatização, punição e vigilância (Foucault, 1999).

Fica perceptível nesse processo que o poder do Estado não é a única forma de poder e que a relação entre o poder e o saber tem forte influência nos diversos discursos. Dentro desse contexto, as tensões e os conflitos no processo de implementação do PROVAB revelam-se por intermédio da resistência de setores da medicina, que exercem, em alguns momentos, força maior que o aparato estatal e isso, contraditoriamente, dentro da própria estrutura do Estado através da Comissão Nacional de Residência Médica (CNRM), comissão responsável por regular a formação de especialistas no Brasil por meio da modalidade de Residência Médica.

O setor privado, apesar de não compor o aparato estatal, exerce também uma força instituída que influencia nas escolhas dos médicos e muitas vezes dificulta a priorização das necessidades do sistema de saúde. A própria cultura liberal da profissão, o assalariamento autônomo e a formação médica instituída pelas universidades, citados nos estudos de Campos (2006) e Feuerwerker (2002) também são vetores de poder-saber que influenciam no senso comum da sociedade e dos estudantes de medicina nas suas escolhas, contribuindo para o quadro demográfico atual.

Uma outra questão que se mostra em disputa é a respeito da concessão de bônus de $10 \%$ nas provas de Residência para os participantes do PROVAB, aprovado em resolução pela CNRM/MEC. Esse incentivo para participação no programa, entretanto, só é concedido após processo avaliativo do desempenho do profissional inserido no programa por meio de uma instituição supervisora vinculada à Universidade ou a Escolas de Saúde Pública, da própria equipe e do gestor local da unidade à qual o médico faz parte, e de uma autoavaliação, com posterior certificação pelo Ministério (Brasil, 2011b). Aqui pode-se perceber um ponto de conflito por meio do conceito de meritocracia, compondo várias visões e percepções a respeito do assunto e com vários acontecimentos instituintes nesse processo, agregando novos atores, como é o caso do poder judiciário que também atua neste processo. Para outros atores, o conceito de mérito é entendido exclusivamente como resultado do esforço individual em armazenar um conjunto de saberes científicos abordados por meio de um processo seletivo de livre concorrência.

A visão de meritocracia predominante corrobora com a lógica atual de formação dos especialistas no país, o que difere da visão de alguns segmentos que acreditam na vivência como aprendizagem, 
contribuindo para uma visão mais ampliada do profissional em relação à Atenção Básica. Quanto à priorização de atuação dos profissionais na Atenção Básica, apesar de existir uma comissão que decide sobre estes processos, a CNRM (Comissão Nacional de Residência Médica), que deveria orientar o processo regulatório de acordo com as necessidades do SUS, contraditoriamente há uma submissão às regras do mercado, que passa a ser um grande indutor das escolhas dos médicos que se submetem às regras do jogo para ingressarem em uma residência médica. A ausência de uma regulação estatal mais intensa tem trazido algumas consequências como o elevado percentual de ociosidade na ocupação de vagas da Residência de Medicina e Comunidade, chegando a, aproximadamente, 70\%, em razão do alta falta de interesse dos médicos nessa especialidade não atrativa do ponto de vista do mercado.

Todo esse cenário tem contribuído para a proliferação dos chamados "Med Cursos", verdadeiros cursinhos preparatórios para os programas de residências uma vez que o critério de seleção mais relevante é a prova que reforça o modelo de memorização estabelecido no curso de medicina, muitas vezes, desarticulados com a realidade e com as necessidades de saúde da população.

Apesar de a Residência Médica ser uma das mais eficientes estratégias de fixação de profissionais de saúde, acaba sendo um funil a que poucos têm acesso e muitos ficam de fora, entrando no mercado de trabalho com grande oferta de emprego e altos salários (Giradi, Pierantoni, Dal, 2012).

O modelo de formação médica atual por sua vez positivista, centrado no biológico, tendo o hospital como o lugar central de formação do médico, traduz em todos os ciclos acadêmicos o poder-saber disciplinar.

A lógica de aprendizagem fragmentada e tendo como objeto o saber científico tem produzido "uma relação de dependência do aluno com o docente, este visto como fonte quase exclusiva de saber, e uma baixa autonomia do aluno na compreensão dos problemas de saúde da população" (Comissão Interinstitucional de Avaliação do Ensino Médico, 2000 apud Santos, 1998, p.97) em contraposição a uma visão onde o objeto da formação médica são as necessidades de saúde da população e que os diversos saberes articulados em torno desse objeto servem como insumos do processo pedagógico e, o docente passa a ter um papel de tutor e mediador da aprendizagem e o aluno sai da condição passiva para de sujeito do processo de aprendizagem (Feuerwerker, 2002; Santos, 1998).

Essa relação de poder - saber disciplinar se transpõe para as práticas profissionais e acabam fabricando o médico que hoje temos na sociedade, atuando nas relações do trabalho do médico com as equipes de saúde e a comunidade e, no caso do PROVAB, por exemplo, de diversas maneiras, na discussão de mérito, nas atividades de supervisão exercida pelas instituições supervisoras e na atuação do médico no território.

As relações de trabalho operam, portanto, nas relações de poder sejam de opressão, sejam de subordinação, sejam de liberdade ou de alteridade, dependendo do modo como é compreendido o sentido e o significado do trabalho.

No âmbito das ações educativas do PROVAB, constituída pela supervisão e pelo Curso de Especialização em Saúde da Família e Atenção Básica, observamos que os conteúdos abordados, assim como o processo avaliativo, buscam o fortalecimento da Atenção Básica.

“A Estratégia de Saúde da Família se apresentou para mim como meio de ganhar experiência na área depois de formada e como intermeio para a residência antes pensada em pediatria. Após menos de seis meses de trabalho me encantei pelo programa e todas as suas possibilidades de poder colocar o que aprendi na prática, olhar o paciente de forma integral e não apenas como uma doença". (médica vinculada ao PROVAB)

No artigo intitulado "Um ensaio sobre o médico e suas valises tecnológicas: fazendo um exercício sobre a reestruturação produtiva na produção do cuidado", Merhy et al. (2000) trazem como contribuição a este debate, a reflexão sobre saberes e tecnologias, trabalho vivo e trabalho morto para o ato de cuidar.

As três valises citadas por Merhy são a da mão, responsável pelos procedimentos e pelas técnicas realizadas, a da cabeça, na qual cabem os saberes da epidemiologia e da clínica e a outra valise que está no espaço relacional, fruto do encontro entre trabalhador e usuário, onde contém tecnologias leves 
para lidar com este campo das relações. A interação com o usuário e a tensão entre as três valises contribuem com os processos de captura do trabalho vivo pelo trabalho morto e as diferentes formas de realizar o trabalho médico e os atos em saúde na perspectiva do cuidado ou na perda da dimensão cuidadora.

Na obra do autor, o trabalho vivo é visto como o trabalho criativo, instituinte e inovador, desempenhado pelo profissional que usa a sua subjetividade para criar novas formas de fazer, utilizando diversas tecnologias de acordo com as necessidades apresentadas e, o trabalho morto é caracterizado como o trabalho instituído, que corresponde a todos aqueles produtos-meios que nele estão envolvidos como matéria-prima e que são resultados de um trabalho humano anterior (Merhy, Onocko, 1997).

Merhy (2002) diferencia ainda os saberes em não estruturados, semiestruturados e estruturados. No primeiro, estão as tecnologias leves utilizadas no campo relacional como o acolhimento, a produção de vínculo entre profissional e usuário e entre usuário e equipe, o compromisso com a resolutividade e a multiprofissionalidade, entre outros. Já os saberes semiestruturados estão no campo das tecnologias leve-duras, em que se destacam os saberes da clínica e da saúde pública dentro de uma visão voltada para Atenção Básica. Por fim, os saberes estruturados compõem as tecnologias duras e se referem a procedimentos e técnicas necessárias para algumas situações que ocorrem nas unidades de saúde (Exemplo: sutura, curativo, espirometria, eletrocardiograma).

O saber - fazer do médico e do supervisor do PROVAB, assim como a maneira como estes articulam as tecnologias, os saberes e suas valises tecnológicas na interação com os usuários - pode revelar uma prática clínica centrada em procedimentos e técnicas ou no cuidado à saúde. Apesar de não termos o objetivo de afirmar nenhuma hipótese a respeito, observamos, por meio de fragmentos de falas, relatos e análises no webportfólio, nas oficinas e reuniões e nos instrumentos de supervisão um recorte focado na doença onde os saberes estruturados e semiestruturados, assim como as tecnologias duras e leveduras, citados por Merhy (2002) ainda prevalecem na prática clínica dos profissionais.

De acordo com o relato do supervisor:

“Na prática de atenção à saúde e educação permanente, observa-se ainda a atenção com foco na doença, a inexperiência, a insegurança na prática clínica, o pouco conhecimento sobre abordagem familiar, abordagem comunitária, educação em saúde, SUS, dificuldades em habilidades de comunicação, processo de trabalho e gestão da agenda/tempo, incluindo o horário para estudo". (relato dos supervisores)

Observando os relatos e as descrições qualitativas e quantitativas, identificamos as diversas faces da supervisão, que vai desde o supervisor fiscalizador, com "conhecimento superior" e aferidor de conceito ou corretor de uma conduta, reproduzindo o modelo pedagógico hegemônico das escolas médicas, no qual se estabelece a relação de detentor do saber científico.

Outra dimensão de supervisão é a do supervisor apoiador ou facilitador dos processos de aprendizagem, comprometido com o trabalho e com uma relação de "alteridade" entre os sujeitos trabalhadores, buscando compartilhar saberes e práticas para mudança nos processos de trabalho, produzir autonomia do profissional e comprometimento com a vida.

Essa relação de poder é reproduzida na relação médico-paciente, em que, muitas vezes, o paciente é objeto da prática médica e não sujeito. A interação médico-paciente pode também estabelecer uma relação de autoridade de um sobre o outro, mediada pelo saber científico e não pelas necessidades de saúde e pela subjetividade de cada indivíduo frente ao sofrimento.

Toda essa visão é decorrente do modelo de sociedade e assegura a base de sustentação do modelo assistencial vigente, sendo a escola médica um locus de poder-saber que interfere de forma significativa no perfil do médico formado e na proposta de formação no PROVAB.

A relação assimétrica de poder no âmbito da educação entre docentes e aprendizes com incorporação tecnológica acrítica vai moldando as relações de poder explicitados por meio do saber médico baseado em homogeneização do conhecimento, normalização, hierarquização e centralização (Foucault, 1999). 
Em proposta pedagógica, baseada na mediação do processo de aprendizagem, ambos os atores aprendem com o processo, cabendo ao supervisor muito mais a função de mediador do processo de aprendizagem. É necessário, portanto, reconhecer que esses profissionais atuam nos territórios de prática com as suas valises ou caixas de ferramentas que eles acumulam com a vida. Apoiar estes profissionais para que eles ampliem as suas caixas de ferramentas ou valises (Merhy, 2002) podem agregar novos saberes e novas práticas em saúde a partir do encontro entre o trabalhador e usuário.

Essa perspectiva pode gerar um deslocamento desses profissionais de uma postura centrada em procedimentos, na queixa-conduta, para uma atitude agenciadora do cuidado.

A educação permanente passa, então, a ser estratégica para mudar o processo de trabalho e investir em práticas cuidadoras (Merhy, 2002). A educação permanente, diferentemente de outras ações educativas como cursos, Telessaúde e outros é um dispositivo que propõe articular aprendizado no trabalho e a partir do trabalho, produzindo implicações e compromissos com a mudança do processo de trabalho e com as necessidades de saúde da população.

Para produzir potência, as políticas de provimento devem ter o compromisso com a mudança do processo de trabalho. Para que isso ocorra, é necessário o aprendizado mútuo entre a academia e os serviços, na busca de compromisso com a mudança da realidade sanitária local e a perspectiva da educação permanente, cujo conceito ainda não foi devidamente incorporado pelo SUS, produzindo fatores de confusão com as práticas educativas no âmbito da educação continuada.

\section{Inquietações do presente, rumo ao futuro: a regulação da formação profissional e do trabalho por parte do Estado}

Analisando esses processos de forma dinâmica e dialética, observamos que o PROVAB está, a cada momento, passando por mudanças, seja no âmbito das modelagens de contratação, seja na proposta educacional. Novos formatos para o PROVAB 2013 foram incorporados, um deles refere-se ao profissional médico, que passa a receber bolsa federal pelo trabalho, na modalidade trabalhador-estudante, com a obrigatoriedade de cursar a Especialização em Atenção Básica. Essa dimensão de bolsa de estudo, que articula trabalho e educação, tem a perspectiva de fortalecer o aspecto de formação e de educação do PROVAB.

O PROVAB, apesar de todas as dificuldades no seu processo de implantação, está contribuindo para o provimento de médicos nas diversas regiões do Brasil. Como avanços dessa experiência, podemos destacar a possibilidade de levar assistência médica à população, ampliando o acesso às ações e serviços de saúde nas regiões mais remotas do país e a integração ensino-serviço por intermédio da inserção das universidades no SUS por meio das atividades de supervisão.

Entre as dificuldades relatadas na primeira versão do programa, destacam-se as desistências dos profissionais em participar do programa, a dificuldade de comunicação entre os diversos atores, a falta de integração dos diversos componentes do programa, ainda operando de forma fragmentada e desarticulada, concepção de supervisão médico - centrada e com viés avaliativo e punitivo.

Embora prover médicos seja necessário, a agenda do campo temático do trabalho e da gestão da educação na saúde se constitui uma agenda estratégica para o SUS. A regulação do trabalho e da formação profissional previsto na Constituição Brasileira e na Lei 8.080/1990, ainda não foi implementada, apesar da política de provimentos de médicos trazer alguns elementos regulatórios na agenda.

A análise dos processos de implementação do PROVAB nos revela, entretanto, que, além de uma agenda no campo da macropolítica, há a necessidade de formular propostas que considerem a micropolítica dos processos produtivos, considerando que "todos fazem gestão, todos fazem educação permanente e todos de uma certa maneira governam" (Merhy, 2013) ao definirem condutas dentro dos seus consultórios, nas visitas domiciliares e na dinâmica da vida.

A incorporação da educação permanente como estratégia para superar a dicotomia ensino e serviço, revela-se como um dispositivo potente para a mudança do modelo de atenção e do cuidado à saúde da população. 
O fortalecimento da proposta de supervisão sob a perspectiva do apoio às equipes e de forma multiprofissional, nos princípios da educação permanente, reconhecendo, cooperando com os trabalhadores do SUS, entre eles os profissionais do PROVAB, produzindo agenciamentos, pode ser um importante fator de mudança das práticas e do cuidado em saúde.

Desse modo, dialogar sobre quais modelos de formação profissional e de educação permanente se quer construir e quais as disputas e os interesses, assim como definir qual marco regulatório na gestão do trabalho e da educação para o país, são desafios importantes a serem discutidos em uma agenda propositiva nesse campo temático.

\section{Colaboradores}

Os autores Mônica Sampaio de Carvalho e Maria Fátima de Sousa participaram da elaboração do artigo de sua discussão e da redação e da revisão do texto.

\section{Referências}

BRASIL. Secretaria de Atenção à Saúde. Departamento de Atenção Básica. Política Nacional de Atenção Básica. Brasília: Ministério da Saúde, 2012a. (Série E. Legislação em Saúde).

BRASIL. Decreto 7.508/2011, de 28 de junho de 2011. Regulamenta a Lei no 8.080, de 19 de setembro de 1990, para dispor sobre a organização do Sistema Único de Saúde - SUS, o planejamento da saúde, a assistência à saúde e a articulação interfederativa, e dá outras providências. Brasília, 2011a. (Série E, Legislação de Saúde, p.7).

BRASIL. Portaria Interministerial n 2.087, $1^{\circ}$ de setembro de 2011. Institui o Programa de Valorização do Profissional da Atenção Básica. Diário Oficial [da] República Federativa do Brasil, Poder Executivo, Brasília, DF, 2 set. 2011 b. Seção 1, p.92.

Lei 8.080 , de 19 de setembro de 1990. Dispõe sobre as condições para promoção, proteção e recuperação da saúde; a organização e o funcionamento dos serviços correspondentes e dá outras providências. Diário Oficial [da] República Federativa do Brasil, Poder Executivo, Brasília, DF, 20 set. 1990. Seção 1, p.18055.

CAMPOS, G.W.S. Os médicos e a política de Saúde: entre a estatização e o empresariamento - a defesa da prática liberal da Medicina. São Paulo: Hucitec, 2006. 
CAMPOS, G.W.S. Um método para análise e co-gestão de coletivos: a constituição do sujeito, a produção de valor de uso e a democracia das instituições: o método da roda. São Paulo: Hucitec, 2000.

CAMPOS, C.V.A.; MALIK, A.M. Satisfação no trabalho e rotatividade dos médicos do Programa de Saúde da Família. Rev. Adm. Publica, v.42, p.347-68, 2008.

CAMPOS, F.E.; MACHADO, M.H.; GIRARDI, S.N. A fixação de profissionais de saúde em regiões de necessidades. Divulg. Saude Debate, n.44, p.13-24, 2009.

CAPOZzOLO, A.A. No olho do furacão: trabalho médico e o Programa de Saúde da Família. 2003. Tese (Doutorado em Saúde Coletiva) - Faculdade de Ciências Médicas, Universidade Estadual de Campinas, Campinas. 2003.

CECCIM, R.B. Onde se lê recursos humanos da saúde, leia-se coletivos organizados de produção da saúde: desafios para a educação. In: PINHEIRO, R.; MATTOS, R. (Orgs.). Construção social da demanda: direito à saúde, trabalho em equipe, participação e espaços públicos. Rio de Janeiro: Cepesc, 2005. p.161-80.

. ARMANI, T.B.; ROCHA, C.F. O que dizem a legislação e o controle social em saúde sobre a formação de recursos humanos e o papel dos gestores públicos no Brasil. Cienc. Saude Colet., v.7, n.2, p.373-83, 2002.

CONSELHO FEDERAL DE MEDICINA. Demografia médica no Brasil: dados gerais e descrição das desigualdades. Brasília: CFM, 2011. v.1.

DONNANGELO, M.C.F. Medicina e sociedade: o médico e seu mercado de trabalho. São Paulo: Pioneira, 1975.

DONNANGELO, M.C.F; PEREIRA, L. Saúde e sociedade. 2.ed. São Paulo: Duas Cidades, 1979.

FEUERWERKER, L.C.M. Residência médica e as estratégias de mudanças da educação médica no Brasil. 2002. Dissertação (Mestrado em Saúde Pública) - Faculdade de Saúde Pública/USP, São Paulo. 2002.

FOUCAULT, M. Microfísica do poder. Rio de Janeiro: Graal, 1996.

Em defesa da sociedade. São Paulo: Martins Fontes, 1999.

GIRARDI, S.N.; PIERANTONI, C.R.; DAL POZ, M. Formação, regulação profissional e mercado de trabalho em Saúde. In: FUNDAÇÃO OSWALDO CRUZ et al. (Orgs.). A Saúde no Brasil em 2030: diretrizes para prospecção estratégica do sistema de saúde brasileiro. 22.ed. Rio de Janeiro: Editora Fiocruz, 2012. p.157-68.

GONÇALVES, R.B.M. Raízes sociais do trabalho médico. 1978. Dissertação (Mestrado) - Faculdade de Medicina, Universidade de São Paulo, São Paulo. 1978.

Práticas de saúde: processos de trabalho e necessidades. São Paulo: Cadernos Cefor,Secretaria Municipal de Saúde de São Paulo, 1992.

MACIEL FILHO, R. Estratégias para distribuição e fixação de médicos em sistemas nacionais de saúde. 2007. Tese (Doutorado em Política, Planejamento e Administração em Saúde) - Instituto de Medicina Social e Preventiva, Universidade Estadual do Rio de Janeiro, Rio de Janeiro. 2007.

MERHY, E.E. Gestão para a produção do cuidado em redes de atenção à saúde. In: ENCONTRO REGIONAL SUL DA REDE UNIDA, 2013, Londrina. Palestra ... Londrina, 2013. Partes 1 e 2. Disponíveis em: <https://www.dropbox.com/s/ mi1 viossy7kbklr/Emerson\% 20Elias\% 20Merhy\% 20-\% 20Encontro\% 20Regional\% 20Sul\% 20da\% 20Rede\% 20Unida\% 20-\% 20.mp4>; <https://www.dropbox. com/s/qzptbpb4nhh9vpk/Emerson\% 20Elias\% 20Merhy\% 20-\% 20PARTE\% 2002\% 20Encontro\% 20 Regional\%20Sul\% 20da\%20 Rede\%20Unida.mp4>. 
Acesso em: 17 nov. 2013.

MERHY, E.E. Saúde: a cartografia do trabalho vivo. São Paulo: Hucitec, 2002.

. Um ensaio sobre o médico e suas valises tecnológicas: contribuições para compreender as reestruturações produtivas do setor Saúde. Interface (Botucatu), v.4, n.6, p.109-16, 2000.

MERHY, E.M.; ONOCKO, R. Agir em saúde: um desafio para o público. São Paulo: Hucitec, 1997.

MINAYO, M.C.S. O desafio do conhecimento: pesquisa qualitativa em saúde. 9.ed. São Paulo: Hucitec, 2006.

Pesquisa social: teoria, método e criatividade. 23.ed. Petrópolis: Vozes, 2004.

SANTOS, B.S. Pela mão de Alice: o social e o político na pós-modernidade. São Paulo: Cortez, 2000.

Introdução a uma ciência pós-moderna. Rio de Janeiro: Graal, 1989.

SANTOS, R.C. Saúde todo dia: uma construção coletiva. São Paulo: Hucitec, 1998.

Se analiza como ha enfrentado Brasil la carencia de médicos y los intentos de superar la situación de forma articulada con las políticas de salud y estrategias de formación y fijación de esos profesionales, de acuerdo con las necesidades del Sistema Único de Salud (SUS). Se consideró como estudio de caso el PROVAB (Programa de Valorización de la Atención Básica) creado por el Gobierno Federal en 2011, cuyo objetivo es proporcionar profesionales de salud a las localidades que los necesitan, destacándose las siguientes ofertas del programa: puntuación del 10\% en los exámenes de prácticas después de evaluación del profesional y actividades estructuradas de educación a distancia y supervisión. El PROVAB se analizó dentro del contexto actual de la política de Gestión del Trabajo y de la Educación en la Salud, buscando entender su implementación mediante discursos, movimientos, acontecimientos y datos cualitativos y cuantitativos puestos a disposición por el Ministerio de la Salud. Se señalan caminos para el desarrollo de la gestión del Trabajo y de la Educación en la Salud en Brasil.

Palabras-clave: PROVAB. Atención Básica a la Salud. Educación médica. Práctica profesional. Educación permanente. 